Association for Information Systems AIS Electronic Library (AISeL)

ECIS 2000 Proceedings

European Conference on Information Systems

2000

\title{
Structured Case: A Methodological Framework for Building Theory in Information Systems Research
}

\author{
J. M. Carroll \\ The University of Melbourne, jcarroll@staff.unimelb.edu.au \\ P. A. Swatman \\ Deakin University
}

Follow this and additional works at: http://aisel.aisnet.org/ecis2000

\section{Recommended Citation}

Carroll, J. M. and Swatman, P. A., "Structured Case: A Methodological Framework for Building Theory in Information Systems Research" (2000). ECIS 2000 Proceedings. 42.

http://aisel.aisnet.org/ecis2000/42

This material is brought to you by the European Conference on Information Systems (ECIS) at AIS Electronic Library (AISeL). It has been accepted for inclusion in ECIS 2000 Proceedings by an authorized administrator of AIS Electronic Library (AISeL). For more information, please contact elibrary@aisnet.org. 


\title{
Structured-case: A methodological framework for building theory in information systems research
}

\author{
J. M. Carroll \\ Department of Information Systems \\ The University of Melbourne \\ Victoria, Australia \\ jcarroll@staff.dis.unimelb.edu.au \\ and \\ P. A. Swatman \\ School of Management Information Systems \\ Deakin University
}

\begin{abstract}
This paper presents a methodological framework, structured-case, that assists IS researchers to undertake and assess theory building research within the interpretive paradigm, and explains its value in achieving convincing explanations that are strongly linked to both the research themes and data collected in the field.
\end{abstract}

\section{INTRODUCTION}

The previous decade has seen an increase in the range of research approaches that are considered acceptable for information systems (IS) research. There is now widespread acknowledgement of qualitative research as a valuable and valid research approach [1][2]. However, qualitative research covers a plurality of research paradigms (positivist, interpretive and critical), within which there are many research methods (such as case studies, field studies, ethnography and action research), research processes and techniques. Silverman [3:7] argues that "there is no agreed doctrine underlying all qualitative social research"; the common element of qualitative research is the collection of data in the form of words and images, which is analysed by methods that do not include statistics or quantification [4].

Although methodological pluralism is valuable in providing alternative perspectives on the design, development and use of information systems [5], this breadth of research approaches poses theoretical and practical challenges for IS researchers. The theoretical issue concerns assuring the quality of qualitative IS research. Having come to terms with the requirements for quality research within the paradigm and method chosen, the practical issue involves how the research is actually performed. These challenges are of particular concern for researchers who are:

- inexperienced in qualitative IS research (either entering the field of qualitative research, or performing it infrequently)

- moving between the various research methods. Researchers should carefully match the research approach to the research topic, situation and available resources, rather than sticking to just one approach.

- intent on demonstrating the quality, validity and plausibility of their particular research approach to an audience unfamiliar to the chosen approach. One problem with qualitative research in general is demonstrating the linkage between the data collected and conclusions drawn: as [6:539] observes, "a huge chasm often separates data from conclusions". Strong, believable conclusions need to be linked clearly to the data from which they are derived.

The approach we have taken to these issues of performing and evaluating qualitative IS research is the development of a methodological framework. In this paper, we provide the background to the development of the methodological framework, present a comprehensive discussion and graphical representation of the framework, describe how it assists IS researchers to build theory from data gathered in the field, and outline its value for achieving sound, interpretive IS research.

\section{BACKGROUND}

The benefits of the methodological richness of qualitative research are balanced by the difficulties of coming to grips (as a practitioner, consumer and evaluator) with the diversity of approaches and their associated requirements for quality, validity and rigor. This paper presents a methodological framework in which research processes, tools and techniques can be selected and implemented in order to build theory in IS. The application of the framework is illustrated in this paper by reference to interpretivist field research. In particular, we focus on building interpretive understanding, as described by [7]. Lee sees that field research may involve three levels of understanding:

- subjective understanding, the every day understanding of social actors, or the research participants

- interpretive understanding, the researcher's understanding of the participants' subjective 
understanding

- positivist understanding, the researcher's understanding of the 'objective facts' of a situation, which is necessarily informed by interpretive understanding.

There are many different research strategies (collecting data through document study, interviews, observation or participation, and analysing data using hermeneutics, phenomenology or grounded theory) for building interpretive understanding. Our particular interest involves building theory from field work that examines professional practices in the field. Such field research enables the development of deep understanding of the complex interaction of people, processes and technology within organisations.

We have called the methodological framework 'structuredcase' [9]:

- 'structured', in reference to the use of a formal process model comprising three structural components: a conceptual framework, a pre-defined research cycle and a literature-based scrutiny of the research findings, to assist the researcher in theory building. The conceptual framework represents the researcher's aims, understanding and theoretical foundations and the research cycle guides data collection, analysis and interpretation; together, these structures make the research process visible, record its dynamics and document the process by which theory is induced from field data. The literaturebased scrutiny compares and contrasts the outcomes of the research process with a broad range of literature to support or challenge the theory built.

- 'case', used in the broad sense of what is being studied, rather than the narrower sense of the case study research method [10]. A case may be a person, group of people, organisation, process or information system.

Criteria for performing rigorous IS case studies using positivist [11] [12] and interpretivist [13] [14] paradigms have been presented in the literature. These works outline what is needed, rather than how to achieve it. Strategies have been suggested for performing case study research (Yin's case study protocol [15]) and building theory from case studies (Eisenhardt's eight step roadmap [6]), but these do not adequately describe the theory building process. Inducing theory from qualitative data is adaptive and highly iterative; neither of these strategies suggests the flexibility and opportunism required when studying a poorly understood situation. Although Eisenhardt [6:546] sees the theory building process as "strikingly iterative" and describes "constant iteration backward and forward between steps", her roadmap is a simple eight step framework that progresses from 'Getting Started' to 'Reaching Closure' [6:533]. The tabular representation of the framework fails to capture the inherent recursion and backtracking of the research process, the ongoing refinement of the initial research questions and constructs, and the continuing comparison of data with emergent themes, the literature and outside expertise. By picturing theory building as a linear path, the roadmap may be deceptive to a researcher needing guidance when facing difficult decisions or overwhelmed by the masses of data accumulated in qualitative research. In addition, both Yin and Eisenhardt are working within the positivist paradigm and address issues of validity and rigour from that viewpoint.

Structured-case builds on these existing works and extends them, in order to provide a more usable and useful representation of the process of inducing theory from field work, for researchers working within the interpretivist paradigm. It provides an overall framework that includes constructing and articulating a preliminary conceptual structure, collecting and analysing data, and reflecting on the outcomes to build knowledge and theory. Structured-case assists at a high level of abstraction; the researcher must select and specify the concrete research details within the chosen research method. The particular approach taken within the interpretivist paradigm will influence the selection of techniques used for collecting and analysing the data (such as document analysis, interviews, observation, participant observation and use of contextual analysis, protocol analysis, and grounded theory) within the structured-case framework.

Structured-case makes two contributions to IS research. Firstly, it presents a coherent and integrated methodological framework for building theory from interpretive research, in a similar way Eisenhardt's roadmap does for positivist theory building. Structured-case represents the true, iterative nature of building theory from qualitative data. Theory building involves a poorly-understood path [6] of moving from broad, ill-defined research themes, collecting masses of data, analysing and interpreting them to build theory and then reporting the research findings. Structured-case provides a descriptive guide for this recursive research process; its clear and coherent structure enables researchers to orient themselves during the difficult process of performing highquality qualitative research. We stress the word 'guide': structured-case is not a cookbook or a prescriptive method, but rather a framework within which research is tailored according to the skills, philosophy and experience of the researcher and the characteristics of the research phenomena, context and project. Obviously, building theory from qualitative data is much more complex than simply following a structure or framework; we argue, however, that structuredcase is a valuable extension to existing research frameworks (such as those of [6][15]), and is specifically directed towards the interpretivist, rather than positivist, paradigm.

Secondly, structured-case assists researchers in achieving and demonstrating high-quality qualitative research. There are various descriptions of the requirements for inducing theory 
from interpretivist research (see [4][13][14]); structured-case provides an effective bridge between understanding these requirements and actually satisfying them. In particular, the structural elements of structured-case help researchers to record the dynamics of their research processes, and document the rationale for decisions taken. This assists in providing rich and convincing explanations that are tied to the data, which is a key attribute of sound interpretive research.

\section{STRUCTURED-CASE}

Structured-case has three main elements: the conceptual framework, the research cycle and the literature-based scrutiny of theory built. We outline these elements and discuss how they assist IS researchers in building theory from interpretive research.

\section{The Conceptual Framework}

There has been much discussion about the amount of conceptual content or structure used to guide the initial stages of a qualitative research project [4][6][16][17]. There are two extreme positions:

- effectiveness, where pre-conceived notions are minimised and the researcher is maximally sensitive to concepts arising purely from the data; this implies a research design with little pre-defined structure.

- efficiency, where pre-conceived notions are used to focus the research, and maximum benefit is gained from scarce research resources; this implies a research design with some kind of pre-defined conceptual structure.

An effective research approach, such as grounded theory [4] [16], may involve prolonged periods in the field, collecting huge amounts of data. On the other hand, an efficient approach may limit the researcher's ability to respond flexibly to themes and insights that emerge from the data. Accordingly, qualitative researchers should strive to reach a balance between these two extremes [18:105].

All researchers bring some kind of conceptual structure to the research process. It would be unrealistic to suggest that researchers could or should enter the field devoid of a framework or ideas about the important concepts in their area of interest. Indeed, the requirements of sound research suggest otherwise: a survey of the relevant literature develops the themes of the research and identifies gaps in existing research (see [16] for a dissenting view). By reading the literature, however, researchers colour their views of the research area and are exposed to a range of ideas, concepts and theories. More fundamentally, all researchers interpret the world through some sort of conceptual lens formed by their beliefs, previous experiences, existing knowledge, assumptions about the world and theories about knowledge and how it is accrued. The researcher's conceptual lens acts as a filter: the importance placed on the huge range of observations made in the field (choosing to record or note some observations and not others, for example) is partly determined by this filter. Accordingly, facts are both theoryladen and value-laden [19]. The process of representing this conceptual structure, confronting its underlying assumptions, and making it explicit is one of the keys to high-quality research.

A formally defined conceptual structure is a key element of structured-case, not only in the initial stages, but throughout the research process. We have called this structure the conceptual framework, following Miles and Huberman [17:18], who see that it "explains, either graphically or in narrative form, the main things to be studied - the key factors, constructs or variables - and the presumed relationships between them." The conceptual framework is the researcher's representation of the conceptual structure brought to the research process. We suggest that the conceptual framework is formed from the research themes, existing knowledge about which is gathered from the literature and insights, filtered by a researcher's theoretical foundations:

- the research themes set out the main areas of interest of the research. Unlike deductive scientific research - where the researcher enters the field with tightly constructed research questions or hypotheses inductive, qualitative research begins with broad research themes that are refined through the research process.

- the literature informs the research by providing understanding of current knowledge and theories in the areas of interest; as well, gaps in the literature may highlight areas for further investigation.

- the researcher may gain insights from personal and professional experiences, experts in the research area and from practitioners. Although these insights may provide practical and contextual knowledge, their sources tend to be informal and unpublished.

- the theoretical foundations, or world view, with which every researcher enters the field, comprise beliefs, assumptions and expectations about the world (see [19][20]). An interpretivist paradigm underpins the research effort, placing it in a wider intellectual framework. The process of explicitly expressing the theoretical foundations encourages the researcher to clarify and confront these influences on the research. This occurs not only when constructing the initial conceptual framework, but as part of reflection in every research cycle: the researcher considers the theoretical foundations and their implications throughout the research.

The conceptual framework expresses the researcher's current understanding of the research themes, and so clearly sets out the territory to be explored [17:20]. It depicts the key concepts and relationships of interest, given the researcher's 
particular research paradigm. The conceptual framework is defined not only at the start of the research project. At the end of each research cycle, it is critically examined and revised to incorporate understanding gained about the research themes. It then forms the basis of a subsequent research cycle that will further refine understanding of the research themes. Therefore, the conceptual framework is a series of evolving models that are reviewed and refined over the life of the research project.

\section{The Research Cycle}

Understanding about the research themes expressed in the conceptual framework is accumulated through cycles of research. The structured-case research cycle is conceptualised in four stages, which have been adapted from practice-based models of organisational research and action (the problemsolving cycle of action research [32] and the incremental process improvement wheel [33]). While the four stages are described below as inclusive and separate, in practice they are fluid and ill-defined, allowing much iteration between adjacent stages. Consequently, movement through the cycle does not follow any set, sequential pattern.

Plan. Investigation of the research themes is planned. The research paradigm and the concepts and relationships in the conceptual framework are used to select a research design. Appropriate types of cases and organisations for the research design are identified and ways of gaining access to organisations and informants are outlined. The methods for collecting, recording, processing and analysing data (and related criteria for rigor and validity) are planned, as is the method for reporting the outcomes. This tentative research design guides rather than prescribes the research activities, as qualitative research must be responsive to events in the field.

Collect Data. Data are collected and recorded, guided initially by the plan outlined in the previous stage. It should be noted that, although collecting and analysing the data are modelled as separate stages, in practice they may be closely interrelated. In quantitative research, data collection precedes data analysis whereas in qualitative research they may be viewed as overlapping [6] or even as parts of the one activity [18]. During data collection, the researcher examines and analyses the data; field notes record the researcher's interpretations, which may open up new areas for exploration. As a result, the researcher adjusts the data collection to respond to opportunities, unexpected outcomes and emergent themes, for example, by adding questions to an interview protocol in order to incorporate new themes that have emerged [6:539]. Such adjustments are encouraged because inductive theory building is based on deep understanding, rather than statistical comparisons between data collected through standardised protocols.

Analyse. While there may be significant overlaps between data collection and analysis activities, analysis continues after data collection has ceased. Qualitative research typically involves vast amounts of raw data; analysis is the process of organising and reducing this data so that the researcher can bring meaning to it [18]. Coding is one of the most common approaches to qualitative data analysis. Codes should have some sort of conceptual or structural order, rather than being a random collection of categories [17]. Certainly, the data analysis (and therefore coding) needs to be related to the research themes, so that the findings are linked to the aims of the research project. In structured-case, the conceptual framework expresses the researcher's understanding of the research themes at the start of the research cycle. The concepts in the conceptual framework are used as initial codes, to guide the analysis, along with 'any other' codes to incorporate new themes (for a detailed description, see [29]); this provides the links between the data, the data analysis and the research themes.

Analysis is not a one-off activity but rather an ongoing, iterative task that may involve reading and rereading transcripts many times in order to gain deep understanding of the data and the underlying themes and patterns contained in it. The researcher's initial understanding guides reading of the data and leads to new understanding, which then guides further reading of the data [21]. Throughout the process, it is vital that the researcher is receptive to serendipity or "the discovery through chance by a prepared mind of new findings that were not looked for" [22:ix]. Therefore, while the conceptual framework structures the data collection and analysis, it is not overly restrictive. As analysis continues, new concepts and themes will emerge, and be considered by a receptive researcher.

Reflect. The tendency of researchers to note only confirmatory evidence can be lessened through introspection and reflection [8]. Deliberate reflection and critical analysis of any interpretations are seen as necessary for effective learning and research in action research [23:5]. The 'Deakin school' of critical action research suggests that systematic reflection through discussion with a panel of fellow researchers or a "self-reflective community of researchers" [24:172] enhances the rigor of research. Such reflection is valuable for interpretive research in general. A formal stage of reflection, involving deliberate and critical thought, is performed after the data are analysed. This involves: 
- reviewing the research process, such as methods to collect and analyse data.

- evaluating the outcomes of analysis, including assessing emergent themes, challenging current interpretations and seeking disconfirming evidence for tentative findings.

- reviewing the structures of structured-case. The inputs to the conceptual framework may be re-examined, and the research themes refined. Reflecting on emerging themes may lead to clarification from the literature, practitioners or experts. The researcher may revisit earlier transcripts or even return to an informant to discuss whether the tentative interpretations ring true. As understanding is built, it may be used to illuminate transcripts examined previously, reflecting the view that there is no final meaning of a text, but rather a continuing process of constructing meaning [25].

- looking beyond the data to build theory. The findings do not, of themselves, build theory. Instead, the researcher considers any wider implications of the findings for the research themes; this includes critical review of any theory built to date (thus moving from within-case to across-case analysis, see [6] [15]), and

- changing the conceptual framework to incorporate the knowledge accumulated and theory built. This involves iteration back and forward between the data, the tentative findings and the inputs to the conceptual framework. The rationale for changing the conceptual framework is recorded; this provides internal justification of the research findings. As well, external justification may be provided by a panel of IS researchers, who review the updated conceptual framework and the related rationale (see [24]). The reflection stage ends when the conceptual framework is challenged and confirmed, or revised and updated to include the learning gained in this research cycle. The conceptual framework then forms the basis for a new research cycle.

\section{Theory Building}

Theory building is creative, intellectual work [26:142]. The reflection stage of structured-case involves moving beyond the data to explore ideas, link concepts, note patterns and examine tentative themes. Concepts will be clarified and categorised, and the relationships between categories will be specified, so that theory is induced about the research themes. We use theory in the sense of "a system of interconnected ideas that condense and organize knowledge" [27:30]. Theory can exist at different levels of sophistication or complexity (see [15][22]):

- minor working relationships that are concrete and based directly on observations

- theories of the middle range that involve some abstraction but are still closely linked to observations, and

- all-embracing theories that seek to explain social behaviour.

We are aiming to build theory of the middle range: to discover and discuss relationships between abstract concepts, so as to build a "web of meaning" [27:33] concerning the research themes.

The interplay between the conceptual framework and the research cycle provides for building knowledge and theory, as illustrated in Fig. 1. The initial conceptual framework, CF1, expresses the researcher's current understanding, lays out the research territory and guides the first research cycle. It forms the pre-understanding for the research cycle; at the end of the research cycle, as an outcome of reflection, the conceptual framework is updated to express the understanding gained as a result of that cycle. The new conceptual framework, CF2, then expresses the pre-understanding for the second cycle, as part of a hermeneutic circle. The research cycles produce a series of conceptual frameworks CF1, CF2, CF3 ... CFn,

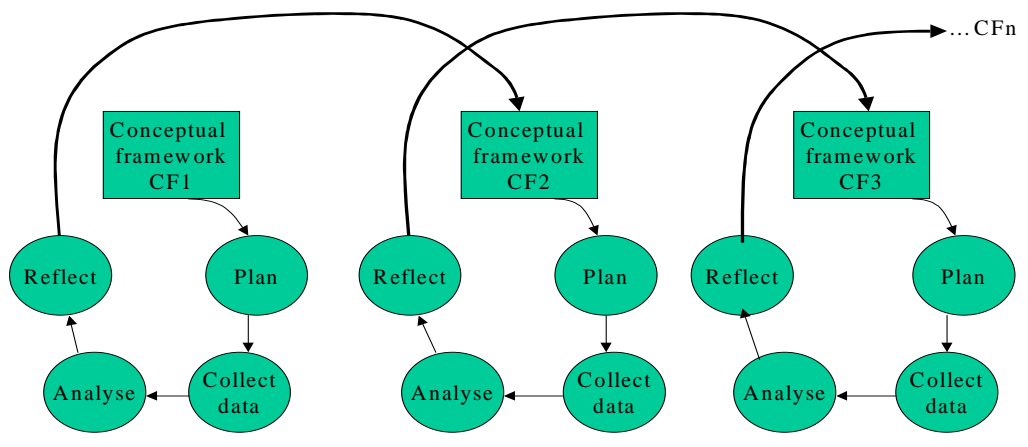

Fig. 1 A spiral towards understanding 
where CFn - the most recent framework - represents the latest version of the theory built to date.

Multiple iterations of these cycles enact a spiral towards understanding, as current knowledge and theory lay the foundations for yet another research cycle that will expand or revise our understanding. The resulting series of conceptual frameworks documents both the process through which the theory was built and its links to the data collected in the field.

In structured-case, theory is built through a conscious process of reflection, focusing on such issues as "What do these findings mean?", "What are the alternative explanations of such findings?", "What disconfirming evidence is there for these explanations?" and "How may these findings relate to the outcomes from previous research cycles?" The researcher returns to the data collected in this (and previous) research cycles, the literature and the insights of experts to extend these reflections. Structured-case builds theory from multiple cases that are used to sequentially enrich and revise the conceptual framework. Therefore, it is particularly suited to building theory of the middle range, as iterations of the research cycle lead to increasingly abstract concepts that have broader applicability than lower level, concrete hypotheses. This iterative theory building process can also be described as moving from substantive theory (applicable to the particular case) to formal theory (may be applied to a variety of situations) [28]. It is not only inductive (moving from the data to theory) but also tightly interrelated with practice: field work leads to theory building which leads to further research into practice. As a result, the theory developed reflects the actions, problems and issues facing practitioners. This is especially relevant for IS, a practical, applied field characterised by rapid changes in practice and an increasing gap between academic research and practice (see [2]).

\section{Literature-based scrutiny of the theory built}

The final element in structured-case involves what [6] calls 'enfolding literature'. The spiral towards understanding is never completed: each research cycle may result in richer and deeper understanding, but there is always more understanding to be gained. At some point, the researcher stops adding cases or revisiting existing data through the research cycles. Glaser and Strauss [28] suggest that the addition of new cases ceases when the researcher reaches theoretical saturation: when many observations have been seen before, and consequently the incremental additions to understanding are slight. Practical considerations are also important here, such as available funding or time. Further reexamination of the data collected ceases when the incremental learning diminishes. At the point where a 'good enough' picture of the phenomenon has been established, the current conceptual framework is compared to a broad range of literature. This differs from the reflection stage in each research cycle, which may involve comparing and contrasting tentative findings with the literature, leading to a revised conceptual framework. The final step in the structured-case theory building is broader, deeper and more challenging. The input from the literature involves a thorough, vigorous and extensive comparison of the findings of the project with a wide selection of the literature (both similar and conflicting). There are two aspects to be considered, the extent to which there is:

- agreement between the findings and the literature, so that the theory built is replicating, consolidating or extending existing theory. Similar findings in different contexts lead to more powerful theory. The support of existing theory (in other fields or disciplines) may lift the theory to a higher conceptual level [6]; more abstract theory may be applicable to a variety of contexts [4].

- conflict between the findings and the literature. The areas and nature of any conflict needs to be examined and persuasive explanations provided for the differences. In interpretive research, such conflicts may arise through different interpretations of similar data or through the particularities of the individual situation; these need to be analysed and discussed by the researcher. Additionally, conflicting literature may encourage the researcher to dig more deeply, reexamine the data with new insights or isolate contextual factors to explain the differences.

The final element in structured-case may lead to critical reassessment of findings or reexamination of the data with new insights, raising the theory built to a more abstract level and increase the applicability of the theory to other contexts. Extension of existing literature and reconciliation with conflicting literature indicate the end of the research process.

\section{An Integrated Methodological Framework}

The integration of the three structural elements of structuredcase, and the inputs and outputs, is illustrated in Fig. 2.

These elements:

- an explicit statement of the initial conceptual framework and the series of conceptual frameworks that documents the process of building theory and knowledge

- a formal research cycle, a stage of which is devoted to reflection, and

- scrutiny of the theory built using the weight of the existing literature

provide an effective roadmap for interpretive research, and allow for critical evaluation of the research outcomes. This ensures that we are building something more substantial than what [20:2] derides as "a letter home to mum". 


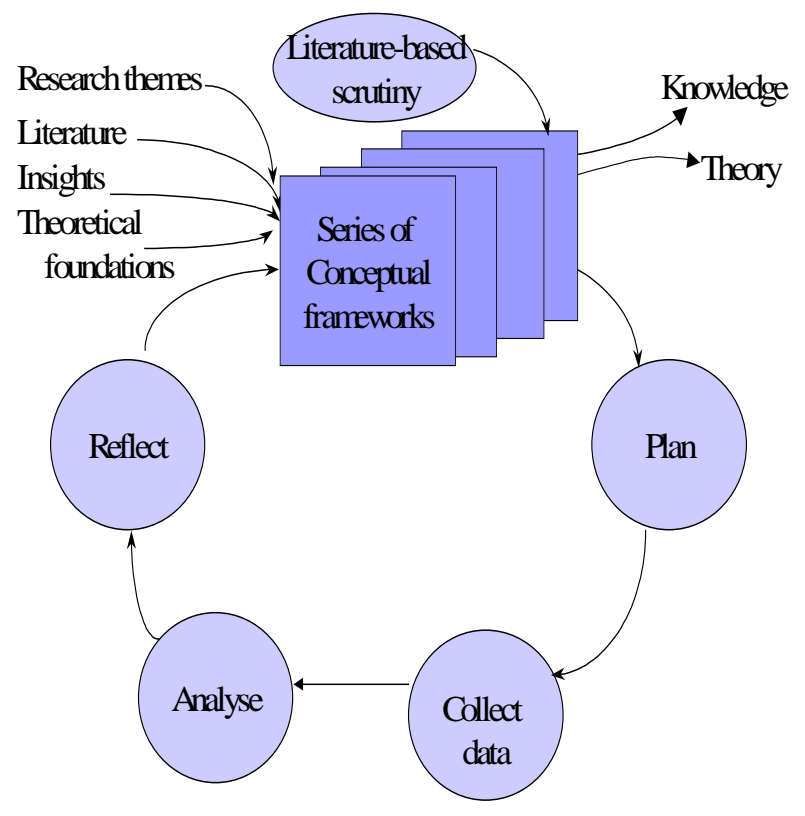

Fig. 2 The Structured-case research method

\section{THE VALUE OF STRUCTURED-CASE}

\section{Quality in interpretive research}

There are numerous views on the requirements for sound interpretive research. Strauss and Corbin [4] suggest that well-constructed theory will be faithful to the area of study, the participants and experts in the area. In hermeneutics research, there should be no absurdities and the actions of the participants make sense [7]. Guba and Lincoln [19] have a more radical view, and question such widely-accepted criteria as credibility, transferability, dependability and confirmability on the grounds of their similarity to positivist criteria. There is a variety of interpretivist approaches, each having its own epistemology. We are not suggesting that structured-case is a vehicle for methodological anarchy (see [34]), but rather are arguing for thoroughness, soundness and transparency of method within a chosen approach. The role of structured-case as a methodological framework means that it does not explicitly address the criteria for quality in each interpretivist research approach,, but rather common requirements relating to evidence, links with the data and the plausibility of explanations. Eisenhardt [6:546] argues that induced theory is likely to be empirically valid when it is tightly linked to the data. Walsham [14] supports this view with his emphasis on the importance of detailed descriptions of how findings were derived.

${ }^{1}$ For an analysis of the benefits of structured-case in a specific interpretivist research method, see [29: 13-15], where it is set against the seven principles of [13] for evaluating interpretivist research from a hermeneutic perspective.
One problem underlying interpretivist approaches is that humans are poor processors of data: our short term memory has limited capacity; we draw conclusions from limited data and pay more attention to recent or vivid evidence and information from influential informants; we have a poor understanding of causality and basic statistical properties, and may not consider disconfirming evidence [6][30]. These shortcomings have significant implications for researchers working within the interpretive paradigm, as intuition and impressions may be misleading and not grounded in sufficiently broad data. Accordingly, it is essential to ensure that findings are based on researchers' interaction with the social actors, their immersion in the research situation and thus their interpretations of the participants' subjective understanding. Structured-case provides a framework that assists researchers to enhance and question the strength of their conclusions, to look for disconfirming evidence, to reflect on the outcomes and to critically evaluate the research methods used. Structured-case enables the provision of rich and convincing explanations of findings that are grounded in the data and well-documented, thus meeting the definition of rigor as "equivalent to grounding, evidence, and persuasiveness" [31].

Structured-case was devised to assist in building theory about poorly understood phenomena. The effectiveness of this integrated framework is demonstrated by the use of structured-case in an interpretivist research project investigating the requirements process as it is enacted in commercial practice (see [9] and the Appendix in [29], which describes two cases and three research cycles, presents the resulting series of conceptual frameworks and outlines the theory built about the requirements process). Structured-case provided significant assistance in undertaking and reporting on the research project.

\section{CONCLUSION}

Structured case is an original synthesis of principles from the qualitative research tradition. It extends existing methods for performing case study research (such as [6][15]), in that its structures are represented in a clear, graphical format that conveys the inherent iteration of the research process. These structures point to the theoretical and practical tasks to be completed before the researcher enters the field, and act as points of reference during the frequent backtracking and recursion of the research process. Structured-case not only helps in performing the research, but also documents the links between the research themes (in the conceptual framework), data (observations and interpretations in the field), the data analysis (coding using the concepts in the conceptual framework, and emergent themes) and the theory and knowledge accumulated through the research process (the series of conceptual frameworks). This documentation captures the dynamics of theory building that are often absent 


\section{from field research reports.}

Structured-case is an addition to the toolkit of IS researchers intent on producing sound research. The increasing use of field work in IS, and the desire to build theory from qualitative data, has highlighted a gap between existing frameworks [6][15] and the criteria for rigorous field research [13][14]. Structured-case helps to close this gap by providing a methodological framework to assist IS researchers working in an interpretive paradigm to build theory from qualitative data.

\section{REFERENCES}

[1] D. Avison, F. Lau, M. Myers, and P. A. Nielsen, "Action research," Communications of the ACM, vol. 42, pp. 94-97, 1999.

[2] M. L. Markus, "The qualitative difference in IS research and practice," in Information systems and qualitative research, A. S. Lee, J. Liebenau, and J. I. DeGross, Eds. London: Chapman \& Hall, 1997, pp. 2-27.

[3] D. Silverman, "Qualitative research: meanings or practice?," Information Systems Journal, vol. 8, pp. 3-20, 1998.

[4] A. Strauss and J. Corbin, Basics of qualitative research - grounded theory procedures and techniques. Newbury Park, CA,: Sage, 1990.

[5] W. J. Orlikowsky and J. J. Baroudi, "Studying information technology in organizations: research approaches and assumptions," Information Systems Research, vol. 2, pp. 1-28, 1991.

[6] K. M. Eisenhardt, "Building theories from case study research," Academy of Management Review, vol. 14, pp. 532-550, 1989.

[7] A. S. Lee, "Integrating positivist and interpretive approaches to organizational research," Organization Science, vol. 2, pp. 342-365, 1991.

[8] E. Babbie, The practice of social research, 5th ed. Belmont CA, Wadsworth, 1989.

[9] J. M. Carroll, L. L. Dawson, and P. A. Swatman, "Using case studies to build theory: Structure and rigour," Proceedings of the 9th Australasian Conference on Information Systems, UNSW, 1998, 6476.

[10] R. E. Stake, "Case studies," in Handbook of Qualitative Research, N. K. Denzin and Y. S. Lincoln, Eds. Thousand Oaks, CA: Sage, 1994, pp. 236-247.

[11] I. Benbasat, D. K. Goldstein, and M. Mead, "The case research strategy in studies of information systems," MIS Quarterly, vol. 11, pp. 368-386, 1987.

[12] A. S. Lee, "A scientific methodology for MIS case studies," MIS Quarterly, vol. 13, pp. 32-50, 1989.

[13] H. K. Klein and M. D. Myers, "A set of principles for conducting and evaluating interpretive field studies in information systems," MIS Quarterly, vol. 23, pp. 67-94, 1998.

[14] G. Walsham, "Interpretive case studies in IS research: nature and method," European Journal of Information Systems, vol. 4, pp. 74-81, 1995.

[15] R. K. Yin, Case study research: Design and methods. Beverly Hills, CA.: Sage, 1984.

[16] B. G. Glaser, Basics of grounded theory analysis. Mill Valley, CA: Sociology Press, 1992.

[17] M. B. Miles and A. M. Huberman, Qualitative data analysis., 2nd ed. Thousand Oaks, CA.: Sage, 1994.

[18] C. Marshall and G. B. Rossman, Designing qualitative research, 2nd ed. Thousand Oaks, CA: Sage, 1995.

[19] E. G. Guba and Y. S. Lincoln, "Competing paradigms in qualitative research," in Handbook of qualitative research, N. K. Denzin and Y. S. Lincoln, Eds. Thousand Oaks: Sage, 1994.

[20] P. Checkland, "Soft Systems Methodology and its relevance to the development of information systems," in Information systems provision: the contribution of Soft Systems Methodology, F. Stowell, Ed. London: McGraw-Hill,, 1995, pp. 1-17.
[21] R. Hirschheim, H. K. Klein, and K. Lyytinen, Information systems development and data modeling. Cambridge: Cambridge University Press, 1995.

[22] R. K. Merton, Social theory and social structure, 3rd ed. New York: The Free Press, 1968.

[23] B. Dick, "So you want to do an action research thesis?," : University of Queensland., 1992.

[24] W. Carr and S. Kemmis, Becoming critical. Education, knowledge and action research. Geelong: Deakin University, 1986.

[25] R. J. Boland, "Phenomenology: A preferred approach to research in Information Systems," in Research methods in Information Systems, E. Mumford et al., Eds.: Elsevier Science Publishers, 1985, pp. 193201.

[26] A. Coffey and P. Atkinson, Making sense of qualitative data. Thousand Oaks: Sage, 1996.

[27] W. L. Neuman, Social research methods: qualitative and quantitative approaches. Boston: Allyn and Bacon, 1991.

[28] B. Glaser and A. Strauss, The discovery of grounded theory: strategies of qualitative research. London: Wiedenfeld \& Nicholson, 1967.

[29] J. M. Carroll and P. A. Swatman, "Structured-case: a rigorous method for building relevant theory in information systems," School of MIS, Deakin University Working Paper 1999/07, 1999. http://mis.deakin.edu.au/research/Working_Papers_99/99_working_pa pers.htm

[30] G. B. Davis, "Strategies for Information Requirements Determination," IBM Systems Journal, vol. 21, pp. 4-30, 1982.

[31] P. G. W. Keen, "Relevance and rigor in information systems research: improving quality, confidence, cohesion and impact," in Information systems research: contemporary approaches and emergent traditions, H.-E. Nissen, H. K. Klein, and R. Hirschheim, Eds.: Elsevier, 1991, pp. 27-49.

[32] G. I. Susman and R. D. Evered, "An assessment of the scientific merits of action research," Administrative Science Quarterly, vol. 23, pp. 582-603, 1978.

[33] W. E. Deming, Out of the crisis. Cambridge: MIT Center for Advanced Engineering Study, 1986.

[34] P. K. Feyerabend, Against method. London: New Left Books, 1975. 